\title{
Effect of ultrafine grinding on functional properties of soybean by-products
}

\author{
Fang Wang ${ }^{1,2}$, Valerii Sukmanov ${ }^{1}$, Jie Zeng ${ }^{2}$ \\ 1 - Sumy National Agrarian University, Sumy, Ukraine \\ 2 - Henan Institute of Science and Technology, Xinxiang, PR China
}

\section{Keywords: \\ Grinding \\ Soybean \\ By-product \\ Functional}

\section{Article history:}

Received 21.11.2018

Received in revised form 24.04.2019

Accepted 28.11.2019

\section{Corresponding author:}

Jie Zeng

E-mail:

zengjie623@163.com

DOI:

$10.24263 / 2304-$

974X-2019-8-4-3

\section{Abstract}

Introduction. The ultrafine grinding technology of soybean by-products can effectively increase the content of dietary fiber in the bean dregs, and improve the taste and quality of the product.

Material and methods. Superfine pulverizer KCW-701S; laser particle size distribution meter BT-9300H; scanning electron microscope. The bean dregs were subjected to ultrafine pulverization treatment at 50,40,30, and $20 \mathrm{~Hz}$, and untreated as a control group.

Result and discussion. The water solubility and expansion of ultrafine powdered soybean by-products has increased, compare with the control group. As the frequency decreased, the water solubility and expansion of the soybean by-products were significant change. When the frequency was $30 \mathrm{~Hz}$, the water solubility was $20.84 \%$, and the expansion was $11.03 \mathrm{~mL} / \mathrm{g}$. As the frequency decrease, the water holding capacity showed a downward trend. When the frequency was $20 \mathrm{~Hz}$, the water holding capacity reached the lowest $6.53 \mathrm{~g} / \mathrm{g}$, and compared with the control group $(10.92 \mathrm{~g} / \mathrm{g})$, the difference was significant $(p<0.05)$. The oil holding capacity was no significant change.

The color of the soybean by-products has a significant change, after ultrafine grinding. The brightness $L^{*}$ value of the soybean byproducts has been greatly improved, and it has changed from the original wheat yellow to the creamy-white. The $a^{*}$ and $b^{*}$ values gradually decreased. The microscopic structure of the soybean byproducts was made changes to scanning electron microscopes. As the pulverization frequency decreased, the soybean by-products powder became finer and smoother. The particle size of the bean dregs gradually reduced. When the frequency was at $30 \mathrm{~Hz}$, the median diameter D50 was $47.95 \mu \mathrm{m}$, but when the frequency was less than $30 \mathrm{~Hz}$, the particle size of the bean dregs increased, and the same as a result of scanning electron microscope.

Conclusion. Ultrafine grinding was used to treat soybean byproducts, in the physical and chemical properties has obvious changes. The water solubility and expansion was significantly improved, and much higher than the control group. The frequency of ultrathin grinding of $30 \mathrm{~Hz}$ is rational, and can be used for ultrafine grinding of soybean by-products and their subsequent use in the production of bakery products. 


\section{Introduction}

China is a main producer of soybean products and the cultivation and processing industry of beans have a long history. Soybean can be made into various products, such as tofu, yuba, ferment soybean and so on [1] (Miao K., 2010). Built on the vigorous development of China's soybean industry, the domestic soybean food industry can produce tens of thousands of tons of wet bean dregs each year, with a residue up to $70 \%$. The development of soybeans has brought great economic benefits of the food industry, which can produce 15 million tons per year [2-4] (Golbitz P., 1995; Ruan C., 2014; Liu X., 2008). soybean by-products is full of nutrients, containing $50 \%$ dietary fiber, $25 \%$ protein, $10 \%$ fat, $33 \%$ isoflavones, slightly higher amino acid content than soy milk, as well as calcium, phosphorus, iron and B vitamins. Therefore, soybean by-products have the nutritional characteristics of high fiber, high protein, low fat, and low reducing sugar, and is rich in mineral elements of high potassium, low sodium, high calcium and high magnesium et al [58] (Li B., 2012; Bowles S., 2006; Iskander F. Y., 1987; Wang D. L., 2010). The main ingredients of the soybean by-products were dietary fiber and protein, with high nutritional and health value, and it is a good dietary fiber raw material. However, the direct consumption of dried soybean by-products was rough, and most of the current soybean by-products were used as animal feeds, even the waste was directly thrown away. On the one hand, it caused pollution to the environment, on the other hand, it also caused waste of resources.

Ultrafine grinding use of mechanical force or fluid dynamics to overcome the internal cohesive force of the solid to break it. In the process of ultrafine grinding, the soybean byproducts are modified by friction, extrusion, collision and other forces [9] (Xiang Z. N., 2006). Ultrafine grinding was based on the principle of micron technology. Can make the product finer and more surface active. Ultra-finely pulverized products of excellent physical and chemical properties, and improved utilization [10] (Liu S. L., 2007). At present, most countries used ultrafine grinding technology to treat pollen, tea, wheat bran, rice bran, peel, rice, soybean, beet pulp, animal bone, seaweed, edible fungus and other raw materials, which can preserve nutrients and improve taste [11] (Zhang M., 2005). Ultrafine grinding technology can be supported in both micron and submicron scales. This technology is being applied to cereals, such as whole wheat flour modification and related technologies [12] (Rosa N. N., 2013).

Nowadays, the ultrafine grinding technology can effectively increase the content of dietary fiber in the soybean by-products, and improve the taste and quality of the product. Therefore, it is necessary to develop and utilize the soybean by-products. In the research fresh bean dregs were used as raw materials, dried by hot air, and the water content was controlled below $10 \%$. Used the small ultrafine grinding $\mathrm{KCW}-701 \mathrm{~S}$, the water solubility, swelling, water holding capacity and oil holding capacity of the soybean by-products were analyzed, and the color, microstructure, particle size and thermodynamic properties of the bean dregs were measured, and the soybean by-products were used in baked goods. It provided a theoretical reference to the further research and application of soybean by-products in baked goods.

The laboratory mainly adopts the ultrafine powder machine $\mathrm{KCW}-701 \mathrm{~S}$ which is specially designed for the ultra-fine grinding and pulverizing processing with variable conditions. The main engine speed and fan speed can be adjusted under the action of the inverter, which can meet the crushing conditions of different requirements. The fineness range is $120-1500$ mesh, the crushing cost is low, and the continuity can work. The inverter adjustment range is $50-20 \mathrm{~Hz}$. As the frequency decreases, the strength of the material is smaller. The principle is as follows: the material enters through the inlet, and is partially 
pressed and ground through the grinding tank. The fineness of the material is caused by the airflow caused by the air-selecting motor, and $90 \%$ of the fine powder of the collecting bucket is effectively collected.

\section{Materials and methods}

\section{Test materials}

Soybean by-products, bought in the local market. Superfine grinding KCW-701S (Beijing Yujie Yucheng Machinery Equipment Co., Ltd.). Laser particle size distribution meter BT-9300H (Dandong Baxter). Scanning electron microscopes: (US FEI company).

\section{Test methods}

Process flows of bean dregs ultrafine powder.

(1) Fresh soybean by-products $\rightarrow$ hot air dried $\rightarrow$ ordinary crushes $\rightarrow$ ultrafine grinding $\rightarrow$ sealed spare

(2) Operation points: The fresh wet soybean by-products were dried, then subjected to ordinary grinding, passed through 40 mesh sieve, and finally the ordinary pulverized bean dregs were subjected to ultrafine grinding, at different frequency, and sealed for use.

(3) Pretreatment: fresh wet soybean by-products are evenly spread to a thickness of about $1 \mathrm{~cm}$ at $50{ }^{\circ} \mathrm{C}$, and dried by hot air. Moisture of dried soybean by-products were controlled below 10\% [13] (Cheng J. J., 2018). Smashed through a 40 mesh sieves and sealed to prevent moisture absorption from the soybean by-products.

(4) Superfine grinding: dry soybean by-products, take 500g into the pulverizer, set different frequency to smash for $8 \mathrm{~min}$, collect different frequency of soybean by-products powder, and set aside.

Test designed. The soybean by-products were treated with different frequencies using an ultrafine grinding. Soy slag was ultra-finely pulverized by adjusting the frequency converter. The frequency range was $50-20 \mathrm{~Hz}$. The smaller the frequency, the finer the powder. The soybean by-products were measured for water solubility, expansion, water holding capacity, oil holding capacity, color, scanning electron microscopes, particle size distribution, and differential scanning calorimetry.

\section{Determination of ultrafine grinding of soybean by-products physical and chemical properties}

Effect of ultrafine grinding on water solubility content of soybean by-products. Refer to [14] (Li M. J., 2015). A sample of $0.500 \mathrm{~g}$ of soybean by-products were weighed and placed in $200 \mathrm{~mL}$ beakers. $50 \mathrm{~mL}$ of distilled water was weighed and placed in a constant temperature water bath at $90{ }^{\circ} \mathrm{C}$ for constant stirring. After $30 \mathrm{mins}$, centrifuge at $3000 \mathrm{r} / \mathrm{min}$ for $15 \mathrm{~min}$, pour the resulting supernatant into a Petri dish, and dry to a constant weight at $105{ }^{\circ} \mathrm{C}$ to weigh the residue (the total mass of the Petri dish and residue - Petri dish quality).

Water solubility $=$ residue mass $\div$ sample quality $\times 100 \%$

Effect of ultrafine grinding on the expansion content of soybean by-products. The measurement method was referred to [15-17] (P. Rupérez, \& Saura-Calixto F., 2001; Chau C. F., \& Huang Y. L., 2003; Turnbull C. M., Baxter A. L., \& Johnson S. K., 2005) Weigh 
$1.000 \mathrm{~g}$ of the sample of a container with a graduated surface, add $10 \mathrm{~mL}$ of distilled water, stir, and let it stand at room temperature for $24 \mathrm{~h}$. Record the volume of the sample at this time.

Calculation method: set the sample mass to $\mathrm{N}_{0}$, and the expanded volume was $\mathrm{N}_{1}$

expansion $=$ volume after expansion $\div$ sample mass $\times 100 \%$

expansion $=\mathrm{N}_{1} \div \mathrm{N}_{0} \times 100 \%$

Effect of ultrafine grinding on the water holding capacity of soybean by-products. Weigh about $0.2 \mathrm{~g}$ of soybean by-products into a centrifuge tube, add $10 \mathrm{~mL}$ of water, stir evenly, place at room temperature for $1 \mathrm{~h}$, centrifuge at $3000 \mathrm{r} / \mathrm{min}$ for $20 \mathrm{~min}$, discard the supernatant, and weight of the centrifuge tube [15, 16] (P. Rupérez, \& Saura-Calixto F., 2001; Chau C. F., \& Huang Y. L., 2003).

Water holding capacity $=$ (centrifuge tube and residue mass after centrifugation centrifuge tube mass - dry weight of sample) $\div$ dry weight of sample

Effect of ultrafine grinding on the oil holding capacity of soybean by-products. Take about $0.2 \mathrm{~g}$ of soybean by-products sample, place it in a constant weight centrifuge tube, add $5 \mathrm{~mL}$ of soybean oil, mix well, and let it stand for $30 \mathrm{~min}$, shaking once every 5 $\mathrm{min}$. After that, centrifuge at $4500 \mathrm{r} / \mathrm{min}$ for $25 \mathrm{~min}$ to remove the upper loose fat and weigh the total mass of the centrifuge tube and residue [18] (Tu Z. C., 2014).

Oil holding capacity $=$ (centrifuge tube and residue total mass - sample quality centrifuge tube quality) $\div$ sample quality.

\section{Characteristics of ultra-micro soybean by-products powder}

Changes in the color of soybean by-products by ultrafine grinding. Refer to [19] (Huang S. Y., 2015). $L^{*}$ was the brightness of the sample (100 was white, 0 was black); $a^{*}$ was the red-greenness of the sample (positive value was red, negative was green); $b^{*}$ was the yellowness of the sample (positive value was yellow, negative value was blue).

Ultrafine grinding on the particle size analysis of soybean by-products. Refer to [20] (Cheng J. J. 2018). 0.5g of soybean by-products powder was placed in a beaker, $30 \mathrm{ml}$ of water was added, stirring was continued and dispersion was carried out using ultrasonic waves, and the obtained suspension was slowly added to a laser particle size analyzer. The refractive index was 1.5 , the control shading ratio was $12 \%$. The median diameter value of the soybean by-products at different frequencies was measured.

Effect of ultrafine grinding on the microstructure of soybean by-products. Refer to [21] (Gao C., 2013) for minor modifications. Weigh a small amount of soybean by-products powder, spread it on the conductive adhesive, put the tray into the ion sputtering apparatus to spray gold for $90 \mathrm{~s}$, use the average current of $15 \mathrm{~mA}$, the vacuum degree was 7-8Pa, the end of the gold spray, take out the tray, transfer to a scanning electron microscope, scan detection, take a magnification of 500 times, take a picture, and save the picture.

\section{Analysis of differential scanning calorimetry of soybean by-products by ultrafine grinding}

Refer to [21] (Gao C., 2013). The thermal stability of the sample was measured and analyzed, used a differential calorimeter. A small amount $(2-5 \mathrm{mg})$ of the sample was weighed into a crucible, and then placed in a pressure tested at room temperature under a lid, and transferred to a differential calorimeter for detection. Measuring range was $25-200{ }^{\circ} \mathrm{C}$, and the temperature increase rate was set to $5{ }^{\circ} \mathrm{C} / \mathrm{min}$. 


\section{Statistical design and data analysis}

All data were assayed at least three times and the results were expressed as mean \pm standard deviation $(\mathrm{X} \pm \mathrm{SD})$. Data and mapping were analyzed used statistical software WPS (Excel), and SPSS analysis software was used to test. The level at which significant differences were reported was setting $p<0.05$.

\section{Results and discussion}

Effect of ultrafine grinding on physical and chemical properties of soybean byproducts

Effect of ultrafine grinding on water solubility of soybean by-products. As can be seen from Figure 1, the ultrafine grinding was used to soybean by-products, the water solubility significantly higher. As frequency of ultrafine grinding decreased, the soybean byproducts powder was fine and the water solubility did not change significantly. However, when the frequency was $30 \mathrm{~Hz}$, the water solubility was $20.84 \%$, which was significantly higher than that of the untreated sample (12.02\%), and the difference was significant $(p<0.05)$. This may be due to the mechanical force of the bean dregs during the pulverization process, and the protein present in the soybean by-products were denatured, resulting in a decrease in water solubility. Secondly, some of the insoluble fiber in the soybean by-products were converted into soluble fiber, and the water solubility was affected to some extent [22] (Zhu K. X., 2010).

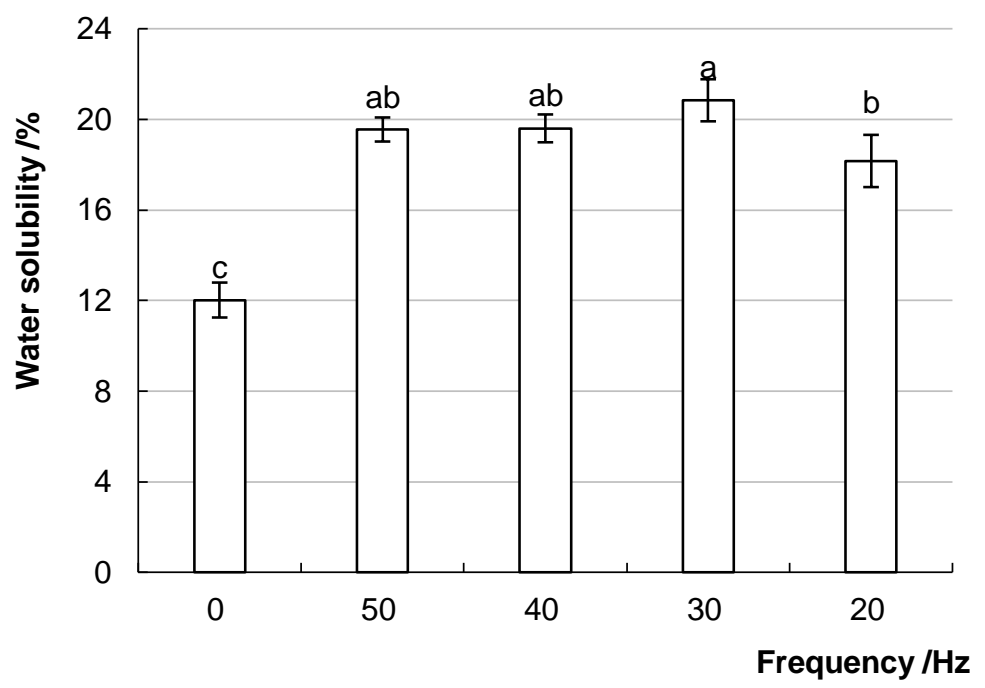

Figure 1. Effect of ultrafine grinding on water solubility of soybean by-products

a-c Different parameter superscripts in the figure indicate significant differences $(p<0.05)$ 
Effect of ultrafine grinding on the expansion of soybean by-products. As can be seen from Figure 2, the ultrafine grinding soybean by-products has higher expansion than the untreated bean dregs $(9.11 \%)$. Because the pulverized soybean by-products residue has a small specific surface area and the sample have high expansion. The frequency of the ultrafine grinding affects the expansion of the soybean by-products, when the frequency was $30 \mathrm{~Hz}$, the expansion property was highest $(11.03 \%)$. when the frequency was lower than 30 $\mathrm{Hz}$, the expansion property was slightly lower. It indicated that the structure of dietary fiber in soybean by-products were damaged in a certain frequency range after ultrafine grinding, and the macromolecular substance decreased with the decrease of frequency, and the expansion of soybean by-products were affected.

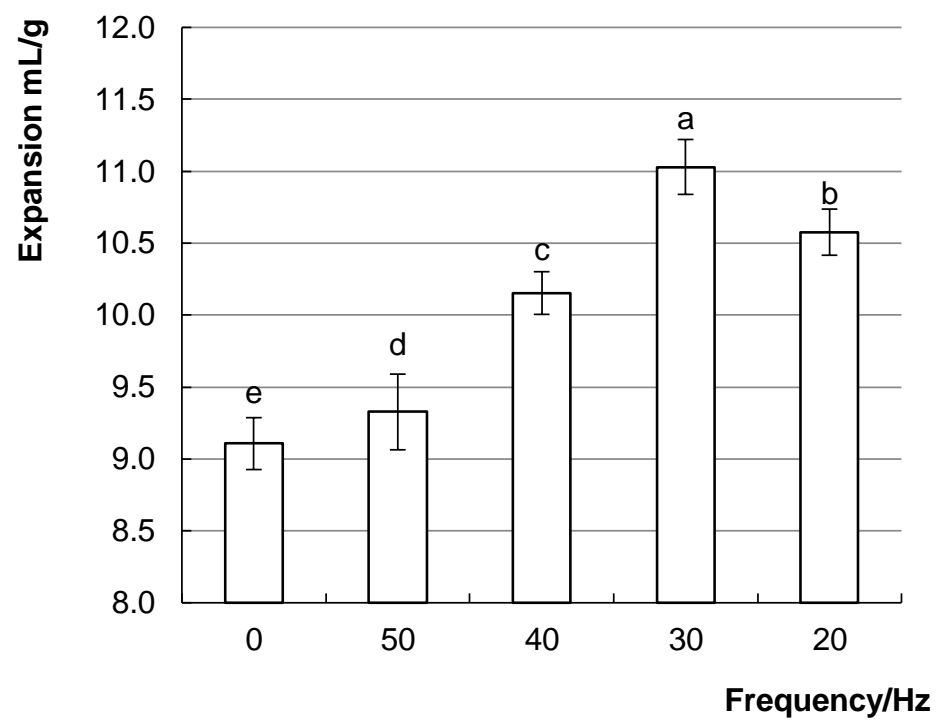

Figure 2. Effect of ultrafine grinding on the expansion of soybean by-products a-b Different parameter superscripts in the figure indicate significant differences $(p<0.05)$

Effect of ultrafine grinding on water holding capacity of soybean by-products. The water holding capacity of the soybean by-products indicates the water absorption capacity of the soybean by-products. As can be observed in Figure 3, the water holding capacity of the soybean by-products decreased with the decreased of the frequency. When the frequency was right on $20 \mathrm{~Hz}$, the water holding capacity of the soybean by-products were at least $6.53 \mathrm{~g} / \mathrm{g}$. It showed that the water holding capacity was linked to the specific surface area and porosity of the soybean by-products. After the ultrafine powder, the porous structure of the surface of the soybean by-products were destroyed, the water holding capacity for reduced. On the other hand, it may be that the particle size of the soybean by-products reduced, the retention capacity of the water and the adsorption capacity was all reduced, and the water holding capacity of the soybean by-products after the ultrafine grinding was gradually decreased. 


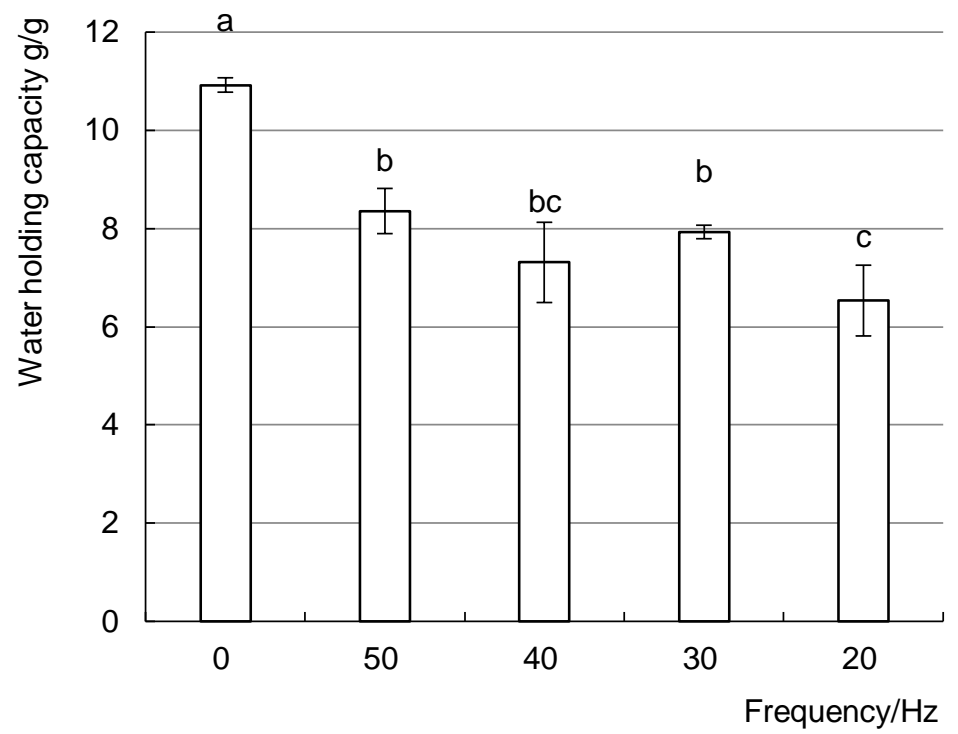

Figure 3. Effect of ultrafine grinding on the water holding capacity of soybean by-products a-c Different parameter superscripts in the figure indicate significant differences $(p<0.05)$

Effect of ultrafine grinding on the oil holding capacity of soybean by-products. The size of the oil holding capacity was mainly related to the structure and content of the protein in the material. As can be observed in Figure 4, the oil holding power of the soybean byproducts were no significant change.

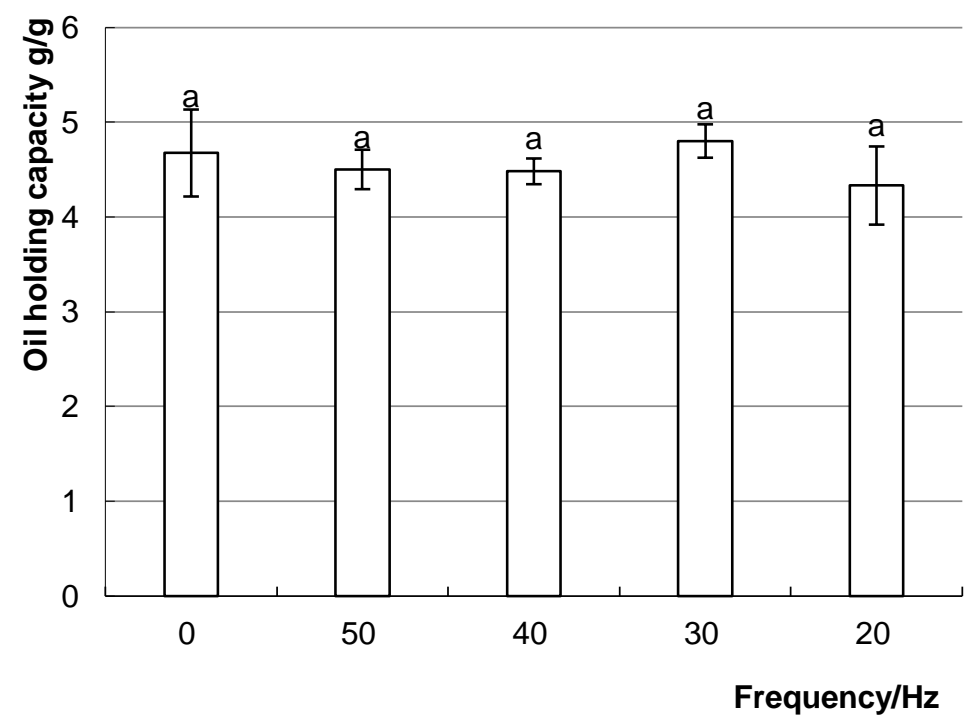

Figure 4. Effect of ultrafine grinding on the oil holding capacity of soybean by-products a-d Different parameter superscripts in the figure indicate significant differences $(p<0.05)$ 
As the frequency of ultrafine grinding decreases, the oil holding capacity gradually decreased. When the frequency reaches $20 \mathrm{~Hz}$, the oil holding capacity was $4.33 \mathrm{~g} / \mathrm{g}$. Compared with control group $(4.68 \mathrm{~g} / \mathrm{g})$, the overall decline was $7 \%$. Because the soybean by-products undermines the structure of the soybean by-products, under the strong agitation of mechanical force, the greater the damage, the oil holding capacity was smaller. This result was significantly correlated with the water holding capacity of the soybean by-products.

\section{Effect of ultrafine grinding on the characteristics of soybean by-products}

Effect of different frequencies on the color of soybean by-products. As can be show in Table 1, the color of bean dregs has changed significantly.

Changes in color at different frequencies

Table 1

\begin{tabular}{|c|c|c|c|}
\hline Frequency/Hz & $L^{*}$ & $a^{*}$ & $b^{*}$ \\
\hline 0 & $80.46 \pm 0.5^{\mathrm{e}}$ & $2.78 \pm 0.2^{\mathrm{a}}$ & $18.79 \pm 0.27^{\mathrm{a}}$ \\
50 & $83.08 \pm 0.09^{\mathrm{d}}$ & $1.85 \pm 0.08^{\mathrm{b}}$ & $17.56 \pm 0.29^{\mathrm{b}}$ \\
\hline 40 & $86.26 \pm 0.86^{\mathrm{c}}$ & $1.48 \pm 0.09^{\mathrm{c}}$ & $15.76 \pm 0.71^{\mathrm{c}}$ \\
\hline 30 & $88.32 \pm 0.29^{\mathrm{b}}$ & $0.98 \pm 0.14^{\mathrm{d}}$ & $13.87 \pm 0.30^{\mathrm{d}}$ \\
\hline 20 & $89.75 \pm 0.37^{\mathrm{a}}$ & $0.64 \pm 0.13^{\mathrm{e}}$ & $13.24 \pm 0.74^{\mathrm{d}}$ \\
\hline
\end{tabular}

Note: The difference between the lowercase letters of the peers indicates that the difference is significant $(\mathrm{P}<0.05)$

Ultrafine grinding increases the brightness of the soybean by-products, and as the frequency decreases, the $L^{*}$ value gradually increases. The $a^{*}$ value and the $b^{*}$ value slightly decreased, and the difference was significant $(p<0.05)$. Therefore, with the stirring of the mechanical force, the ultrafine grinding can increase the color and brightness of the soybean by-products, improve the color of the soybean by-products, and make the flour of the soybean by-products more delicate and shiny [23] (Ren, S. G., 2009).

Effect of different frequencies on the microstructure of ultrafine powder of soybean by-products. It can be seen from Figure 5 that under the same multiples, the Control group dregs have a large, uneven structure and an irregular network structure. When the frequency was at $50-20 \mathrm{~Hz}$, the particles of the soybean by-products became smaller, and the structure of the soybean by-products changes. When the frequency was $50-40 \mathrm{~Hz}$, the particle shape was remarkably small, and the particles gradually become uniform. When the frequency was set to $30 \mathrm{~Hz}$, the particles of the soybean by-products become fine and uniform. When the frequency was $20 \mathrm{~Hz}$, the pulverization force was enormous, and the soybean by-products were fine, but some uneven agglomeration occurs. This was caused by the reduction of the frequency converter, which increases the strength of the pulverization. Under the strong mechanical shearing action, the specific surface area was obviously increased, and some particles were aggregated, so that the porous network structure of the soybean by-products were destroyed. Therefore, it was further verified that as the particle size was further reduced, the retention capacity and adsorption capacity of the water were reduced, resulting in a decrease in the expansion and water holding capacity of the sample after treatment, which was consistent with the measurement results of the properties of the soybean by-products. 

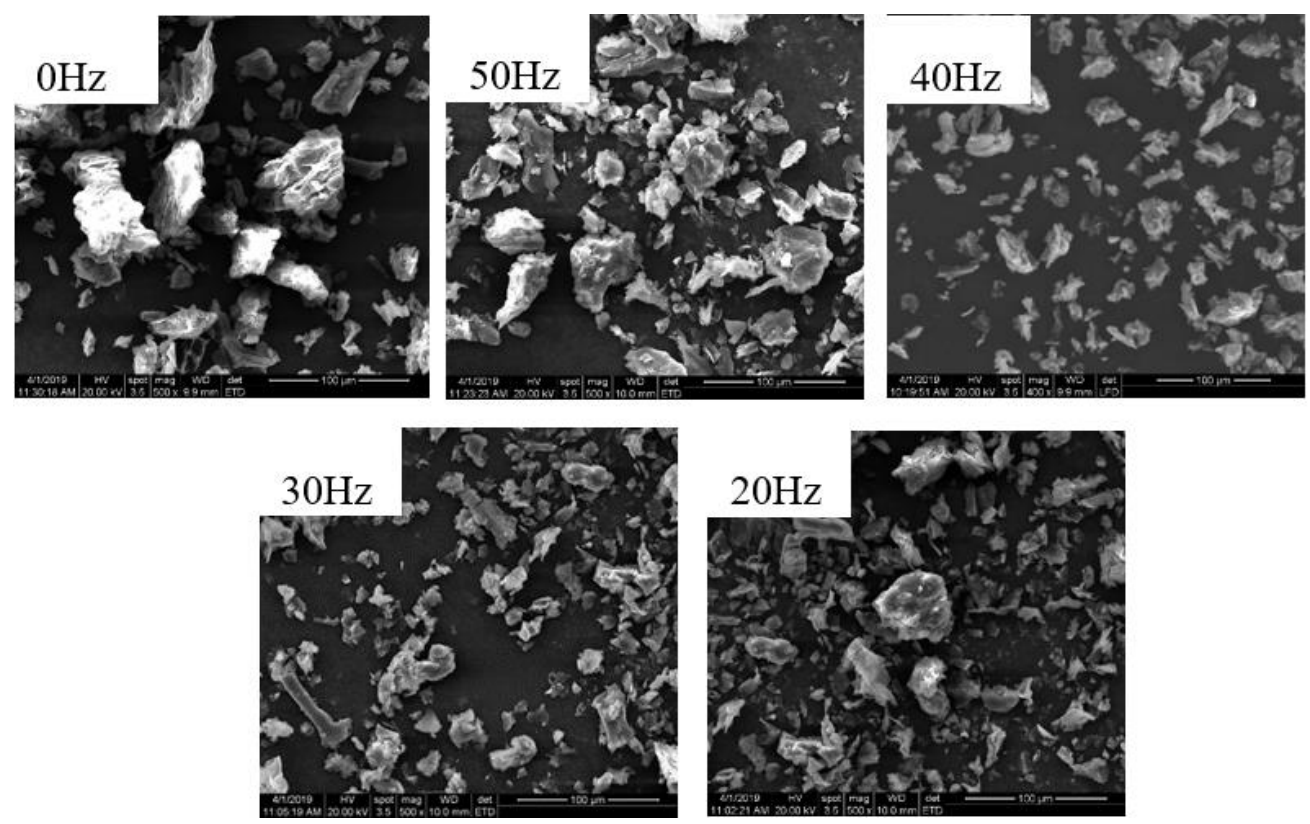

Figure 5. Effect of different frequencies on the microstructure of ultrafine powder of soybean by-products

\section{Effect of different frequencies on the median diameter of ultrafine powder of soybean by-products}

It can be seen from Figbre 6 that the different frequencies of ultrafine pulverization have a great influence on the median diameter of the soybean by-products. As the pulverization frequency decreases, the median particle size of the powder decreases significantly, but when the frequency was higher than $30 \mathrm{~Hz}$, the particle size of the soybean by-products tends to increase. Because the material particles were mainly subjected to centrifugal force and medium viscosity resistance in the body, only the centrifugal force was less than the viscous resistance of the medium, the pulverized material particles pass through the classifying wheel impeller, and as the airflow enters the powder collecting system. The smaller the set frequency, the faster the rotation speed, and the higher the tangential speed of the centrifugal force field, the stronger the centrifugal force field formed. At the same time, the more collisions and the stronger the strength of the material in the machine cavity, the smaller the particle size of the obtained powder [24, 25] (Jin-Xingliu C., 2009; Wang L. D., 2016). However, if the pulverization speed was too large, the total surface area of the powder may increase, the surface energy may increase, and the powder may re-aggregate, resulting in a larger particle size [26] (Xie Y. F., 2016). This phenomenon was consistent with the particle size measurement results. 


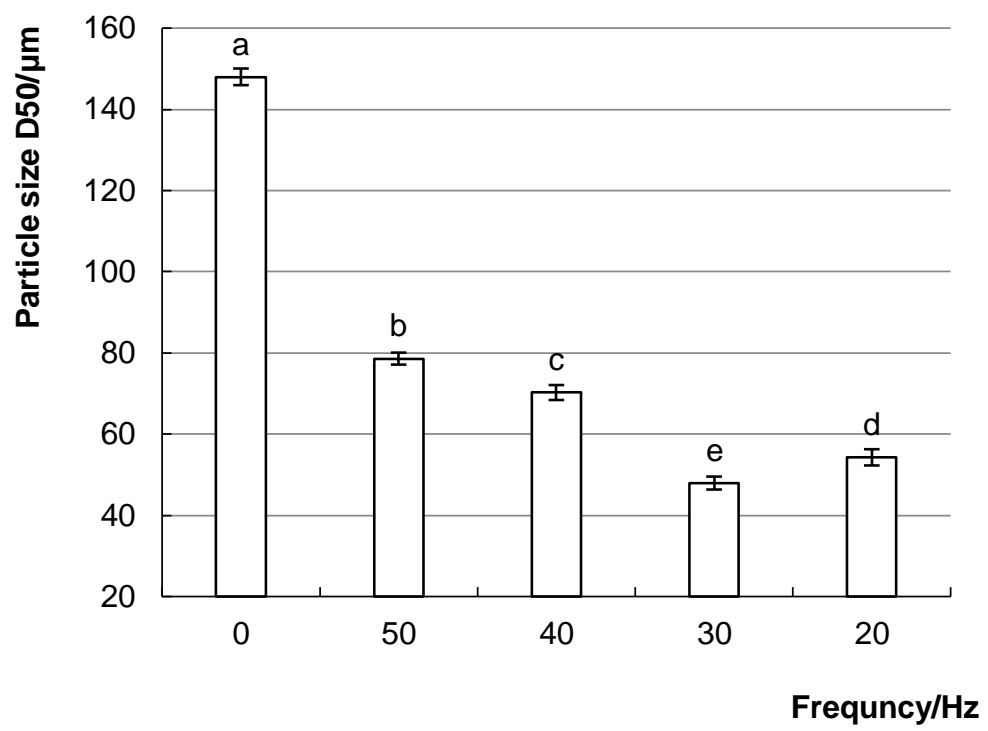

Figure 6. Effect of different frequencies of the median diameter of ultrafine powder of soybean by-products

${ }^{a-d}$ Different parameter superscripts in the figure indicate significant differences $(p<0.05)$

Effect of different frequencies of the thermal stability of ultrafine powder of soybean by-products. As can be seen from Table 2, compared with the original soybean byproducts, As the different frequencies decrease, the onset temperature (To), peak temperature (Tp), and termination temperature (Tc) of the ultrafine grinding soybean by-products changed. The initial temperature of the ultra-finely pulverized soybean residues increased from $32.66{ }^{\circ} \mathrm{C}$ to $34.03{ }^{\circ} \mathrm{C}$; The peak temperature gradually increased from $84.88^{\circ} \mathrm{C}$ to 87.39 ${ }^{\circ} \mathrm{C}$; The termination temperature rises from $138.32{ }^{\circ} \mathrm{C}$ to $139.99{ }^{\circ} \mathrm{C}$; The enthalpy $(\Delta \mathrm{H})$ increased from $150.9{ }^{\circ} \mathrm{C}$ to $174.4{ }^{\circ} \mathrm{C}$. Compared with the original soybean by-products, the initial temperature, the peak temperature, the termination temperature, and the enthalpy value all decreased first and then increased. It shows that the soybean by-products have thermal stability and safety, and there was no unidentified substance, which has no adverse effect on the soybean by-products. This conclusion can be a superfine grinding soybean by-products powder, which was of great significance as a dietary fiber for baking food.

Table 2

Effect of different frequencies of the thermal stability of ultrafine powder of soybean byproducts

\begin{tabular}{|c|c|c|c|c|}
\hline Frequency/Hz & To $\left({ }^{\circ} \mathbf{C}\right)$ & $\mathbf{T p}\left({ }^{\circ} \mathbf{C}\right)$ & $\mathbf{T c}\left({ }^{\circ} \mathbf{C}\right)$ & $\Delta \mathbf{H}\left({ }^{\circ} \mathbf{C}\right)$ \\
\hline 0 & 34.18 & 88.45 & 152.95 & 188.7 \\
\hline 50 & 32.66 & 84.88 & 138.32 & 150.9 \\
\hline 40 & 33.11 & 78.41 & 131.91 & 158 \\
\hline 30 & 33.42 & 73.77 & 129.02 & 153.6 \\
\hline 20 & 34.03 & 87.39 & 139.99 & 174.4 \\
\hline
\end{tabular}




\section{Conclusion}

Ultrafine grinding has a certain influence on the physical and chemical properties of soybean by-products. Compared with the Control group, the water solubility and expansion of soybean by-products by ultrafine grinding had improved. With the decreased of the frequency, the water solubility and expansion of the soybean by-products were significant change, When the frequency was $30 \mathrm{~Hz}$, the water solubility was $20.84 \%$, and the expansion was $11.03 \mathrm{~mL} / \mathrm{g}$. As the frequency decreased, the water holding capacity showed a downward trend. When the frequency was $20 \mathrm{~Hz}$, the water holding capacity reached the lowest $6.53 \mathrm{~g} / \mathrm{g}$, and compared with the control group $(10.92 \mathrm{~g} / \mathrm{g})$, the difference was significant $(p<0.05)$. The oil holding capacity was no significant change.

With the decreased of the ultrafine pulverization frequency, the color $L^{*}$ value of the bean dregs increased, and the $a^{*}$ and $b^{*}$ values gradually decreased. After ultrafine grinding, the $L^{*}$ value brightness was greatly improved, from the wheat yellow color was changed to creamy-white, it indicated that ultrafine grinding can improve the color of the material. Observed by scanning electron microscopy, the microstructure of the ultrafine powder of different frequency has changed significantly. The surface was rough and uneven. With the decrease of the speed, the bean powder becomes fine and the surface of the particles becomes smooth and the powder becomes fine. After the particle size observation, the grain size of the bean dregs after ultrafine pulverization decreased significantly. (The ultra-fine grinding frequency was $30 \mathrm{~Hz}$, the D50 was $47.95 \mu \mathrm{m}$ ). However, when the frequency was lower than $30 \mathrm{~Hz}$, the particle size of the soybean by-products has a tendency to rise significantly. Through the analysis of differential scanning calorimetry of the soybean by-products, the soybean by-products have thermal stability and safety, and there was no unidentified substance, which has no adverse effect on the soybean by-products. Therefore, after analysis of multiple indicators, when the frequency of ultrafine pulverization was adjusted to $30 \mathrm{~Hz}$, the soybean by-products particles were uniform and the texture was fine. This conclusion can provide theoretical basis of the production of soybean by-products biscuits.

\section{References}

1. Mateos-Aparicio I., Mateos-Peinado C., Rupérez P. (2010), High hydrostatic pressure improves the functionality of dietary fibre in okara by-product from soybean, Innovative Food Science \& Emerging Technologies, 11(3), pp. 445-450.

2. Golbitz P. (1995), Traditional soyfoods: processing and products, The Journal of nutrition, 125(3 suppl), pp. 570-572.

3. Ruan C., Ai K., \& Lu L. (2014), Biomass-derived carbon materials for high-performance supercapacitor electrodes, RSC Advances, 4(58), pp. 30887-30895.

4. Liu X., Jin J., Wang G., \& Herbert S. J. (2008), Soybean yield physiology and development of high-yielding practices in Northeast China, Field crops research, 105(3), pp. 157-171.

5. Li B., Qiao M., \& Lu F. (2012), Composition, nutrition, and utilization of okara (soybean residue), Food Reviews International, 28(3), pp. 231-252.

6. Bowles S., Demiate I. M. (2006), Physicochemical characterization of the soymilk by product-okara, Food Science and Technology, 26(3), pp. 652-659.

7. Iskander F. Y. (1987), Maturation stage and mineral content in soybeans, Food chemistry, 24(1), pp. 29-35.

8. Wang D. L., Li B., L U. F., \& Nan H. J. (2010), Analysis of Nutrient Components of Bean Curd Residue, Food and Fermentation Technology, 46(04), pp. 85-87. 
9. Xiang Z. N., Ning Z. N. (2006), Technology of superfine grinding and its application in food industry, Food Research and Development, 17(10), pp. 991-1009.

10. Liu S. L., Wang H. (2007), Application and Research of Superfine Grinding Technique in Food Industry, Drying Technology \& Equipment, 5(1), pp. 35-38.

11. 11. Zhang M., Zhang C. J., \& Shrestha S. (2005), Study on the preparation technology of superfine ground powder of agrocybe chaxingu huang, Journal of Food Engineering, 67(3), pp. 333-337.

12. Rosa N. N., Barron Cécile, Gaiani C., Dufour C. \& Micard Valérie. (2013), Ultra-fine grinding increases the antioxidant capacity of wheat bran, Journal of Cereal Science, 57(1), pp. 84-90.

13. Cheng J. J., Luo C. X, Liu J. (2018), Optimization of preparation technology and characteristics analysis of soybean dregs ultrafine powder, Science and Technology of Food Industry (2), pp. 202-206.

14. Li M. J., Zhang Y. Y,. You,X. R. (2015), Banana biscuit processing technology, Science and Technology of Food Industry, 36(3), pp. 204-208.

15. P. Rupérez \& Saura-Calixto F. (2001), Dietary fibre and physicochemical properties of edible spanish seaweeds, European Food Research and Technology, 212(3), pp. 349-354.

16. Chau C. F., \& Huang Y. L. (2003), Comparison of the chemical composition and physicochemical properties of different fibers prepared from the peel of Citrus sinensis L. Cv. Liucheng, Journal of Agricultural and Food Chemistry, 51(9), pp. 2615-2618.

17. Turnbull C. M., Baxter A. L., \& Johnson S. K. (2005, Water-binding capacity and viscosity of Australian sweet lupin kernel fibre under in vitro conditions simulating the human upper gastrointestinal tract, International journal of food sciences and nutrition, 56(2), pp. 87-94.

18. Tu Z. C,. Chen L. L., Wang H. (2014), Effects of Fermentation and Dynamic High Pressure Microfluidization on Physicochemical Properties of Dietary Fiber in Soybean Residue, Chinese Journal of High Pressure Physics, 28(1), pp. 113-119.

19. Huang S. Y., He Y. W., Qian B. J. (2015), Modification of Insoluble Dietary Fiber in Okara by High Pressure Homogenization and High Hydrostatic Pressure and Functional Properties of the Modified Product, Food Science, 36(15), pp. 81-85.

20. Cheng J. J. (2018), Study on drying method of soybean and its modification technology, (Master's thesis, Shanxi University of Science \& Technology), pp. 1-78.

21. Gao C. (2013), Development and research on high oilgosaccharides-containing okara dietary fiber, (Doctoral dissertation), pp. 1-67.

22. Zhu K. X., Huang S., Peng W., Qian H. F., \& Zhou H. M. (2010), Effect of ultrafine grinding on hydration and antioxidant properties of wheat bran dietary fiber, Food Research International, 43(4), pp. 943-948.

23. Ren S. G., (2009), Studies on the nutrition and physicochemical properties of supermicronized soybean meal powder, (Doctoral dissertation, Si chuan Agricultural university), p. 102.

24. Jin-Xingliu C. (2009), Optimization of dried older stems ultrafine pulverizing of asparagus officinalis, Food \& Machinery, 25(6), pp. 157-159.

25. Wang L, D., Wang W. H. (2016), Processing Technology of Millet Flour by Fluidized Bed Air Superfine Grinding, Farm Products Processing, 11, pp. 30-33.

26. Xie Y. F., Tian S, J., Ma Y. (2014), Effect of ultrafine grinding on functional properties of okara, Food \& Machinery, 2, pp. 7-11. 